\begin{tabular}{|l|l|l|l|l|l|}
\hline J. Tek. Ling. & Vol. 10 & No. 1 & Hal. 01 - 08 & Jakarta, Januari 2009 & ISSN 1441-318X \\
\hline
\end{tabular}

\title{
PENGHITUNGAN EMISI GAS RUMAH KACA (GRK) DARI SEKTOR SAMPAH PERKOTAAN DI INDONESIA
}

\author{
Wahyu Purwanta \\ Peneliti di Pusat Teknologi Lingkungan \\ Badan Pengkajian dan Penerapan Teknologi
}

\begin{abstract}
Indonesia produced 48.8 Mt/year of Municipal Solid Waste (MSW) with population number of 218.8 million and rate of waste generation $0.61 \mathrm{~kg} / \mathrm{cap} / \mathrm{day}$. Most of MSW (40\%) are transported to the Solid Waste Disposal Site (TPA) in urban area. The landfill site which is unmanaged will become a source of the GHGs emission, mainly the methane emission. Based on the Indonesian population, using FOD IPCC Tier-2 method, $\mathrm{CH}_{4}$ generated from MSW sector (landfill only) in 2006 is $109.96 \mathrm{Gg} \mathrm{CH}_{4}$ and will be increased up to $259 \mathrm{Gg}$ in 2010, $504 \mathrm{Gg}$ in 2015 and $1,065 \mathrm{Gg}$ in 2025. The increase number of this $\mathrm{CH}_{4}$ emission is caused by the increase of population number that will increase the waste production and also increase the volume waste that is collected in the disposal area. The future scenario by referring to the national strategic plan which is developed by the Public Work Department is that the waste should be reduced from the source, so the total volume will be reduced by $20 \%$ in 2010. In 2015, refers to the MDGs target, $80 \%$ of the MSW in urban area and $50 \%$ of the MSW in rural area should be transported to the final disposal site. As stated in Solid Waste Management Act No 18/2008 and in accordance with the raw water protection, improvement of landfill quality from open dumping to sanitary landfill or controlled landfill and development of regional landfill are the priority programs with national financial support as an initial investment.
\end{abstract}

Key words : Global Warming, Municipal Solid Waste, GHGs Emission Inventory

\section{PENDAHULUAN}

\subsection{Latar Belakang}

Pemanasan global telah menjadi isu penting saat ini, dimana fenomena ini diakibatkan oleh peningkatan konsentrasi Gas Rumah Kaca (GRK), khususnya $\mathrm{CO}_{2}$ di atmosfer dan telah mengakibatkan berbagai dampak yang merugikan bagi manusia. Berbagai negara, termasuk Indonesia, memberikan perhatian yang besar terhadap dampak pemanasan global. Secara internasional mitigasi pemanasan

global dimuat di dalam Protocol Kyoto yang mengatur kewajiban pengurangan emisi GRK bagi negara industri maju.

Berdasarkan laporan IPCC tahun 2006, sektor limbah (waste sector) turut menyumbang GRK ke atmosfer dimana khusus dari TPA-TPA sampah yang ada berkontribusi antara 3-4\% dari emisi GRK global. Walau terdapat banyak jenis GRK dari sektor persampahan ini, namun yang 
dianggap dominan dan harus ada dalam setiap laporan National GHGs Inventory adalah $\mathrm{CO}_{2}, \mathrm{CH}_{4}$ dan $\mathrm{N}_{2} \mathrm{O}^{11}$.

Gas-gas yang termasuk GRK ini memiliki potensi yang besar dalam pemanasan global yang "potensi" nya diperhitungkan dalam potensi $\mathrm{CO}_{2}$, atau dikenal sebagai Global Warming Potential (GWP). GWP adalah besaran efek radioaktif GRK dibandingkan terhadap $\mathrm{CO}_{2}$, dengan kata lain, GWP ialah indikasi berapa ton emisi $\mathrm{CO}_{2}$ setara dengan satu ton dari setiap GRK lainnya. GWP untuk gas $\mathrm{CH}_{4}$ adalah 21 (relatif terhadap $\mathrm{CO}_{2}$ ) sedangkan $\mathrm{N}_{2} \mathrm{O}$ adalah 310 dan $\mathrm{SF}_{6}$ adalah 23.900, sesuai dengan Laporan Penilaian IPCC (International Panel on Climate Change) yang kedua, nilai dari GWP tidak berubah untuk masa komitmen pertama (2008 2012).

Indonesia sudah meratifikasi Protocol Kyoto via UU No.17 Tahun 2004, dan tidak termasuk dalam negara yang harus mengurangi emisi tetapi dapat berperan dalam mitigasi pemanasan global ini melalui Mekanisme Pembangunan Bersih (CDM) sebagai host country bagi proyek-proyek pengurangan GRK. Karena itulah, sangat penting bagi Indonesia untuk mengkaji berapa besar kemampuan alam maupun berbagai aktivitas sektoral di Indonesia dalam 'menyumbang' (source) maupun 'menyerap' (sink) GRK, termasuk dari sektor persampahan.

\subsection{Tujuan}

Penelitian ini bertujuan untuk menghitung potensi emisi GRK khususnya $\mathrm{CH}_{4}$ dari sektor persampahan dan lebih spesifik lagi emisi dari TPA-TPA sampah yang ada di Indonesia.

\section{METODOLOGI}

Dalam penghitungan emisi GRK, IPCC telah menyusun berbagai metodologi standar untuk menghitung emisi berbagai sektor. Metode tersebut terus diperbaharui dan secara umum dikelompokkan dalam kategori Tier-1, Tier-2 dan Tier-3. Tier-1 adalah metode penghitungan dimana dapat diterapkan pada negara atau wilayah yang tidak memiliki data/parameter persampahan dengan 'record' yang baik. Hampir semua parameter adalah 'default' dari IPCC guideline dalam Tier-1 ini.

Dalam penelitian ini akan digunakan beberapa parameter yang didapat dari hasil penelitian lapangan tetapi beberapa parameter lain tetap menggunakan 'default' IPCC, sehingga metode ini termasuk dalam Tier-2.

Tahap pertama adalah menentukan data awal dan mengganti data 'default' yang ada dengan data yang dimiliki. Jika dalam default IPCC, generation rate sampah adalah $0,7 \mathrm{~kg} / \mathrm{kap} / \mathrm{hari}$ (Asia Tenggara) dan $0,76 \mathrm{~kg} / \mathrm{kap} / \mathrm{hari}$ (Indonesia), maka berdasarkan penghitungan dari berbagai data dan klasifikasi kota didapat angka 0,61 $\mathrm{kg} / \mathrm{kap} /$ hari. Angka ini mendekati perhitungan B.G Yeoh dalam Municipal Solid Waste Generation and Composition (ACST, 2006) sebesar $0,6 \mathrm{~kg} / \mathrm{kap} / \mathrm{hari}^{2}$.

Demikian pula rerata penanganan sampah, berdasar data default IPCC, didapat data $80 \%$ sampah terangkut ke TPA. Angka ini dianggap terlalu besar untuk kondisi saat ini. Dari perhitungan tim dan juga data dari SUSENAS 2004, rerata terangkut ke TPA untuk wilayah perkotaan adalah $40 \%$ sedangkan di pedesaan sebesar $1,5 \%$, sehingga secara nasional sampah terangkut ke TPA sebesar $18 \%$.

Dengan demikian maka parameter penghitungan adalah :

- Jumlah penduduk tahun 2005 : 218.868.791

- $\quad$ Tingkat pertumbuhan penduduk:1,3\%

- Generation rate sampah 0,61 kg/kap/ hari

- Sampah terangkut ke TPA : $18 \%$ (2005) hingga $80 \%$ (2025).

- Komposisi sampah, menggunakan 
data komposisi kota metropolitan dan kota besar hasil survey tim PTL BPPT sebagaimana diperlihatkan dalam Tabel 1, sedangkan parameter DOC ditampilkan dalam Tabel 2 dan beberapa parameter kunci perhitungan di perlihatkan dalam Tabel 3.

Proses penghitungan emisi $\mathrm{CH} 4$ dilakukan dengan IPCC waste model calculation dengan prinsip bangkitan metan $\left(\mathrm{CH}_{4}\right)$ yang timbul dalam suatu TPA diperkirakan dengan persamaan ${ }^{1}$ :

$$
\begin{aligned}
& D D O C_{m}=W \cdot D O C \cdot D O C_{F} \cdot M C F \\
& W=\text { mass of decomposable } \\
& \text { DOC deposited }(\mathrm{Gg}) \\
& D O C=\text { Degradable organic } \\
& \text { carbon in the year of } \\
& \text { deposition, fraction }(\mathrm{Gg} \\
& \mathrm{C} / \mathrm{Gg} \text { waste) }
\end{aligned}
$$

$$
\begin{aligned}
& D O C_{t}= \begin{array}{l}
\text { fraction of } D O C \text { that can } \\
\text { decompose (fraction) }
\end{array} \\
& M C F= C_{4} \text { correction factor for } \\
& \text { aerobic decomposition in } \\
& \text { the year of deposition }
\end{aligned}
$$

Sedangkan potensi timbulan metan dihitung dengan persamaan ;

$L_{\circ}$

\begin{tabular}{|c|c|c|}
\hline Komponen & $\begin{array}{c}\text { 'Default' untuk Asia } \\
\text { Tenggara } \\
(\%)\end{array}$ & $\begin{array}{c}\text { Hasil penelitian } \\
\text { lapangan } \\
(\%)\end{array}$ \\
\hline Papericardboard & 12,9 & 4,07 \\
\hline Textiles & 2,7 & 1,45 \\
\hline Food waste & 43,5 & 16,37 \\
\hline Wood & 9,9 & 0,95 \\
\hline Garden \& Park Waste & - & 49,46 \\
\hline Nappies & - & 3,10 \\
\hline Rubber \& leather & 0,35 & 0,79 \\
\hline Plastic & 6,51 & \multirow{4}{*}{23,81} \\
\hline Metals & 1,45 & \\
\hline Glass & 4,0 & \\
\hline Others & 16,3 & \\
\hline Total & 100,00 & 100,00 \\
\hline
\end{tabular}

$=D D O C_{m} \cdot F \cdot(16 / 12)$

Lo $\quad=\mathrm{CH}_{4}$ generated potential, $\mathrm{GgCH}_{4}$

$D D O C_{m}=$ mass of decomposabie

$D O C, G g$

$\mathrm{F}=$ fraction of $\mathrm{CH}_{4}$ in generated landfill gas (vol. Fraction)

$16 / 12=$ molecular weight ratio $\mathrm{CH} / \mathrm{C}$ (ratio)

Tabel 1. Komposisi Sampah yang Masuk Ke TPA

Sumber: a) 2006 IPCC Guidelines, Waste Sector

b) Rerata dari penelitian di TPA Sarimukti \& Piyungan, 2007 
Tabel 2. Default DOC, Dry Matter, TCC, Fossil Carbon Fraction

\begin{tabular}{|c|c|c|c|c|c|c|c|c|c|}
\hline \multirow[t]{2}{*}{ Component } & \multirow{2}{*}{$\begin{array}{c}\text { Dry matter } \\
\text { content ( } \% \text { of } \\
\text { wet weight) } \\
\text { Default }\end{array}$} & \multicolumn{2}{|c|}{$\begin{array}{l}\text { DOC content in } \\
\% \text { of wet waste }\end{array}$} & \multicolumn{2}{|c|}{$\begin{array}{l}\text { DOC content in } \\
\text { \% of dry waste }\end{array}$} & \multicolumn{2}{|c|}{$\begin{array}{l}\text { Total carbon } \\
\text { content in } \% \text { of } \\
\text { dry weight }\end{array}$} & \multicolumn{2}{|c|}{$\begin{array}{l}\text { Fossil carbon } \\
\text { fraction in } \% \text { of } \\
\text { total carbon }\end{array}$} \\
\hline & & Default & Range & Default & Range & Default & Range & Default & Range \\
\hline Papericardboard & 90 & 40 & $36-45$ & $\overline{44}$ & $40-50$ & 46 & $42-50$ & 1 & $0-5$ \\
\hline Textiles & 80 & $\overline{24}$ & $20-40$ & 30 & $25-50$ & 50 & $25-50$ & 20 & $0-50$ \\
\hline Food waste & 40 & 15 & $8-20$ & $\overline{38}$ & $20-50$ & 38 & $20-50$ & - & - \\
\hline Nood & 85 & $\overline{43}$ & $39-46$ & 50 & $46-54$ & 50 & $46-54$ & - & - \\
\hline Garden \& Park & 40 & $\overline{20}$ & $18-22$ & 49 & $45-55$ & 49 & $45-55$ & $\overline{0}$ & $\overline{0}$ \\
\hline Nappies & 40 & $\overline{24}$ & $18-32$ & 60 & $44-80$ & 70 & $54-90$ & 10 & 10 \\
\hline $\begin{array}{l}\text { Rubber \& } \\
\text { leather }\end{array}$ & $\overline{84}$ & (39) & (39) & $(47)$ & $(47)$ & 67 & 67 & 20 & 20 \\
\hline Plastic & 100 & - & - & - & - & 75 & $67-85$ & 100 & $95-100$ \\
\hline Metal & 100 & - & - & - & - & NA & NA & NA & NA \\
\hline Glass & 100 & - & - & - & - & NA & NA & NA & NA \\
\hline Others & 90 & - & - & - & - & 3 & $0-5$ & 100 & $50-100$ \\
\hline
\end{tabular}

Sumber : 2006 IPCC Guideline, Waste Sector

Tabel. 3 Key Parameter yang digunakan

\begin{tabular}{|l|r|r|}
\hline Key Par am eter & \multicolumn{2}{|c|}{ IPCC default value } \\
\hline Starting year & \multicolumn{2}{|c|}{2005} \\
\hline & \multicolumn{1}{|c|}{} \\
\hline DoC (Degradable organic carb on) & waste by composition \\
\hline (weight fraction, wet basis) & Range & Default \\
\hline Food waste & $0.08-0.20$ & 0.15 \\
\hline G arden & $0.18-0.22$ & 0.2 \\
Paper & $0.36-0.45$ & 0.4 \\
\hline Wood and straw & $0.39-0.46$ & 0.43 \\
\hline Textiles & $0.20-0.40$ & 0.24 \\
\hline Disposable nappies & $0.18-0.32$ & 0.24 \\
\hline Sewage sludge & $0.04-0.05$ & 0.05 \\
\hline & & \\
Industrial waste & $0-0.54$ & 0.15 \\
\hline DOCf (fraction of DOC dissimilated) & & 0.5 \\
\hline
\end{tabular}




\begin{tabular}{|c|c|c|}
\hline \multirow{2}{*}{$\begin{array}{c}\text { Methane generation rate constant }(k) \\
\left(\text { (years }^{-1}\right)\end{array}$} & \multicolumn{2}{|c|}{ Moist and wet tropical } \\
\hline & Range & Default \\
\hline $\begin{array}{l}\text { Food waste } \\
\text { Garden }\end{array}$ & $\begin{array}{l}0.17-0.7 \\
0.15-0.2\end{array}$ & $\begin{array}{r}0.4 \\
0.17\end{array}$ \\
\hline $\begin{array}{l}\text { Paper } \\
\text { Wood and straw }\end{array}$ & $\begin{array}{r}0.06-0.085 \\
0.03-0.05\end{array}$ & $\begin{array}{r}0.07 \\
0.035\end{array}$ \\
\hline $\begin{array}{l}\text { Textiles } \\
\text { Disposable nappies }\end{array}$ & $\begin{array}{r}0.06-0.085 \\
0.15-0.2\end{array}$ & $\begin{array}{l}0.07 \\
0.17\end{array}$ \\
\hline $\begin{array}{l}\text { Sewage sludge } \\
\text { Industrial waste }\end{array}$ & $\begin{array}{l}0.17-0.7 \\
0.15-0.2\end{array}$ & $\begin{array}{r}0.4 \\
0.17\end{array}$ \\
\hline Delay time (months) & & 6 \\
\hline \multicolumn{2}{|c|}{ Fraction of methane $(F)$ in developed gas } & 0.5 \\
\hline Conversion factor, $\mathrm{C}$ to $\mathrm{CH}_{4}$ & & 1.33 \\
\hline Oxidation factor $(\mathrm{OX})$ & & $\overline{0}$ \\
\hline \multicolumn{3}{|l|}{ Parameters for carb on storage } \\
\hline$\%$ paper in industrial waste & & $0 \%$ \\
\hline$\%$ wood in industrial waste & & $0 \%$ \\
\hline
\end{tabular}

\section{HASIL DAN PEMBAHASAN}

Laju pembentukan dan komposisi gasbio di TPA dipengaruhi banyak faktor seperti komposisi sampah, oksigen yang tersedia, kadar air, $\mathrm{pH}$, ketersediaan nutrien, ukuran dan juga kepadatan sampah. Komposisi sampah akan sangat menentukan terhadap kandungan nutrien, $\mathrm{pH}$ dan potensial redoks yang berperan penting dalam proses pembentukan gas. Proses-proses yang menghasilkan gasbio di TPA terkait dengan dekomposisi mikrobiologi dari materi organik di TPA. Pembagian proses-proses tersebut dibagi kedalam empat (4) tahap yakni ; (i) aerobik; (ii) asidogenik; (iii) asetogenik, dan (iv) anaerobik, methanogenik ${ }^{3)}$.

Proses degradasi material organik dalam sampah menghasilkan gasbio utama berupa gas $\mathrm{CH}_{4}$ dan $\mathrm{CO}_{2}$ dengan reaksi yang disederhanakan sbb ${ }^{4)}$;

Degradasi unsur organik di dalam sampah berlangsung secara lambat dalam hitungan tahun dimana selama itu pula gas $\mathrm{CH}_{4}$ dan $\mathrm{CO}_{2}$ terbentuk (first order decay model).

Pada kondisi konstan, laju produksi $\mathrm{CH}_{4}$ tergantung pada jumlah karbon yang terdapat dalam sampah, konsekuensinya jumlah $\mathrm{CH}_{4}$ di suatu TPA akan tinggi pada tahun-tahun awal dan secara gradual akan menurun.

Dari hasil penghitungan data yang ada, sampah dari kebun dan taman akan menghasilkan emisi metan terbesar $(31,9$ $\mathrm{Gg} / \mathrm{thn})$ diikuti sampah sisa makanan (16,7 $\mathrm{Gg} / \mathrm{th})$ kemudian sampah industri $(2,79 \mathrm{Gg} /$ th) dan sampah kertas (2,2 Gg/thn). Tingginya angka emisi dari sampah kebun disebabkan karena volumenya juga terbesar diantara jenis sampah lainnya. Selain itu sampah kebun juga memiliki nilai DOC 0,2 (jika berupa dedaunan) dan dapat menjadi juga 0,4 jika berupa kayu dan ranting. Pada kasus sampah makanan, walau nilai DOC 0,2, tetapi persentase di TPA cukup kecil. Hal ini terjadi karena umumnya sampah -

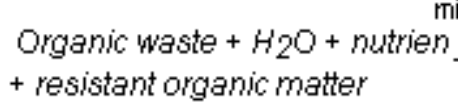


makanan sudah berkurang saat dibuang ke TPA. Sampah rumah tangga pada umumnya sampah sisa makanan masih cukup tinggi. Besaran emisi untuk setiap komponen sampah dapat dilihat pada Gambar 1.
Dari perhitungan juga didapat, jika digunakan data tahun 2005 di atas, maka pada tahun 2006 akan dihasilkan emisi gas metan sebesar 109,96 Gg/th dan akan meningkat menjadi 259,03 di tahun 2010 dan $504 \mathrm{Gg}$ di tahun 2015.

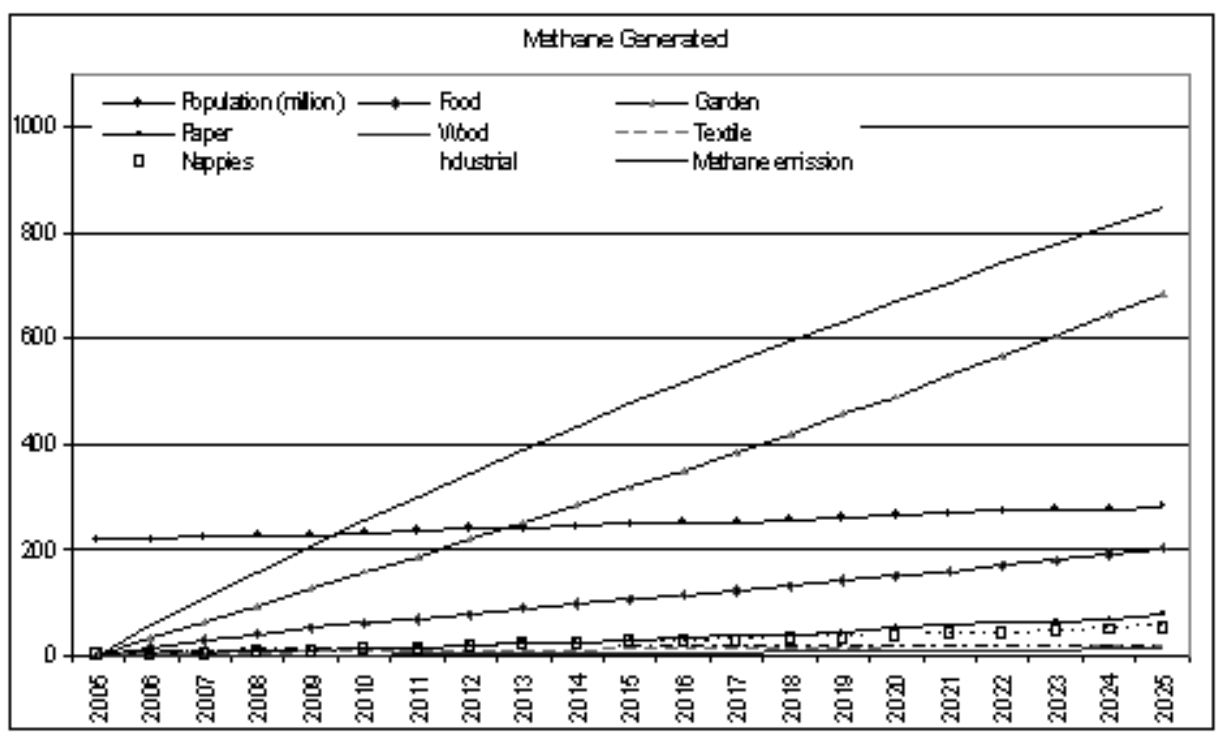

Gambar 1. Emisi Gas Metan dari Beberapa Jenis Sampah Perkotaan

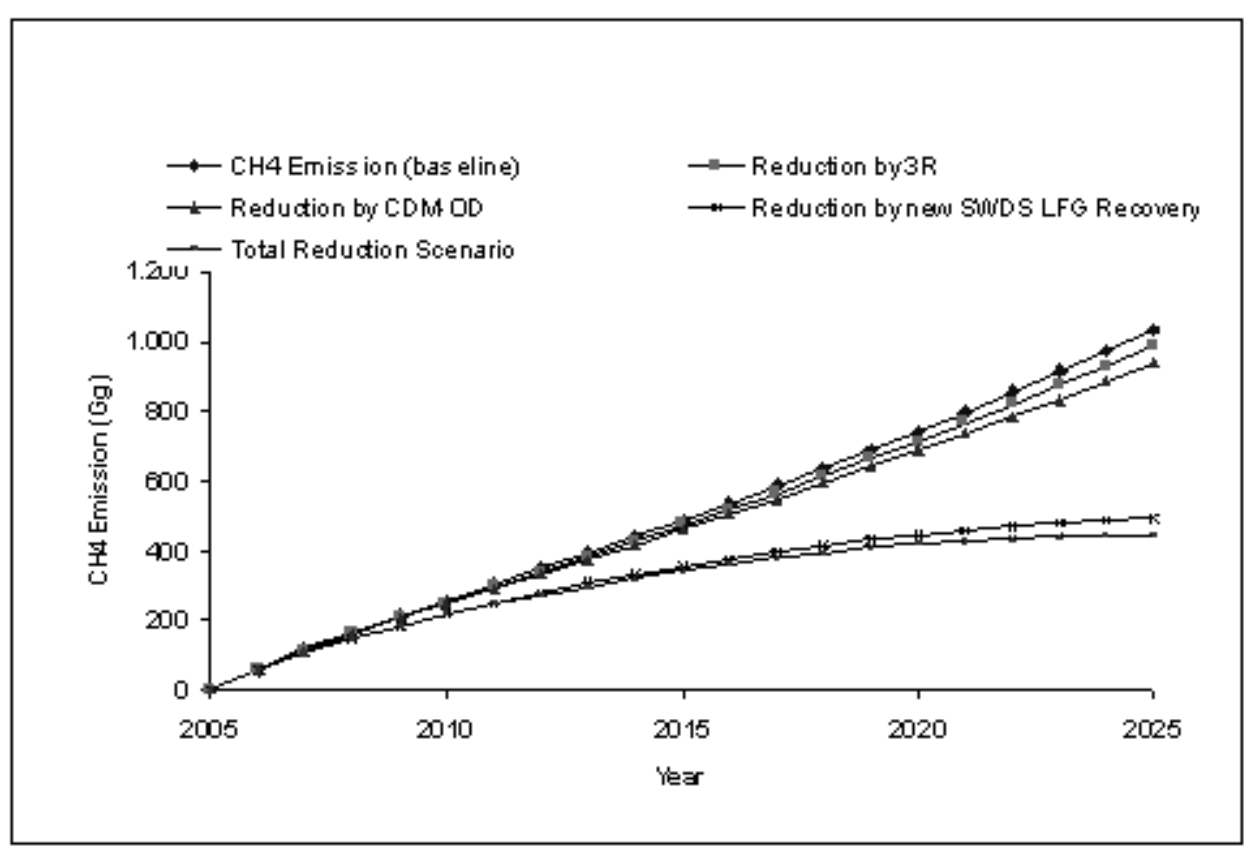

Gambar 2. Total Emisi Metan dari TPA Sampah di Indonesia dan Skenario Mitigasi 
Angka-angka emisi ini didapat dengan memperkirakan jumlah timbulan sampah yang timbul akibat pertambahan penduduk maupun perubahan gaya hidup masyarakat itu sendiri. Jumlah sampah yang diproduksi diperkirakan sebesar 48,7 juta ton per tahun. Dapat dibandingkan dengan hasil hitungan World Bank tahun 2005 yang menghitung potensi sampah dan emisi gas metan di 17 kota besar di Indonesia dimana jumlah sampah yang dihasilkan mencapai 10 juta ton/tahun dengan potensi emisi gas metan sebesar 404 juta $\mathrm{m}^{3} /$ tahun $^{5}$. . Kondisi TPA di Indonesia umumnya boleh dikata "basah" baik karena air hujan di saat musim hujan ataupun karena komposisinya yang hampir $50 \%-70 \%$ berupa sampah yang mudah terurai (organic degradable). Hal ini secara hipotetik TPA sampah di Indonesia sangat berpotensi menghasilkan gas $\mathrm{CH}_{4}$ dalam jumlah yang banyak.

Sudah menjadi kewajiban setiap negara, disamping menyampaikan angka-angka emisi GRK (baseline), juga perlu disampaikan rencana (skenario) mitigasi. Dengan diberlakukannya UU no. 18 tahun 2008 tentang pengelolaan sampah, maka dalam waktu 5 tahun sejak ditetapkan, setiap kota/kabupaten harus membangun sanitary landfill (untuk kota besar) dan controlled landfill (kota sedang dan kecil) guna menggantikan sebagian besar TPA yang ada yang masih open dumping. Perubahan sistem penanganan sampah di TPA ini diharapkan dapat lebih mengendalikan emisi metan misalnya dengan me-recovery gas yag ada. Selain itu amanat dalam UU Persampahan adalah perlunya dimasyarakatkan teknik $3 R$ (reduce, reuse dan recycle) guna mengurangi volume sampah yang dibuang ke TPA. Dengan meningkatnya jumlah sampah yang dikelola dengan prinsip $3 R$, diharapkan emisi GRK juga akan berkurang.

Gambar 2 memperlihatkan total emisi GRK dan kemungkinan upaya penurunannya, dimana penerapan teknik sanitary landfilll dengan LFG recovery
(Landfill Gas Recovery) akan memberikan reduksi yang cukup signifikan. Sebaliknya dengan lambatnya sosialisasi 3R (dimana hingga saat ini hanya $2 \%$ dari total sampah yang dikelola), maka tingkat reduksi GRK dari cara $3 R$ juga sangat rendah, kecuali ada perubahan pola hidup yang sangat signifikan di masyarakat.

\section{KESIMPULAN}

- TPA sampah merupakan sumber emisi GRK dimana gas metan $\left(\mathrm{CH}_{4}\right)$ merupakan gas dominan. Gas ini selain sebagai sumber penyebab pemanasan global juga berpotensi untuk dimanfaatkan sebagai energi dengan mekanisme pembangunan bersih (CDM).

- Potensi gas metan dari sektor sampah di Indonesia sangat besar yakni sekitar $109,96 \mathrm{Gg}$ per tahun dimana terdapat I.k 400 TPA yang hampir semuanya beroperasi secara open dumping. Sebagian besar gas ini dihasilkan dari proses degradasi sampah taman, kayu dan sampah sisa makanan.

- Tingginya potensi gas metan ini disebabkan kondisi TPA Indonesia yang umumnya 'basah' akibat iklim dan juga komposisi sampah organiknya yang hampir $60 \%-70 \%$.

- Beberapa upaya mitigasi gas metan yang dapat dilakukan antara lain : sosialisasi teknik 3R, recovery LFG dari TPA eksisting, dan pembangunan TPATPA sanitary landfill guna menggantikan TPA open dumping sesuai amanat UU no. 18 tahun 2008.

\section{DAFTAR PUSTAKA}

1. Eggleston S., L. Buendia, M. Kyoko, T. Ngara, 2006, "2006 IPCC Guidelines for National Greenhouse Gas Inventories", Vol 5 Waste, IGES

2. Yeoh. B.G, 2006, Municipal Solid Waste Generation and Composition, Asean Committee on Science \& 
Tecnology, Sub Committee on Non Conventional Energy Research

3. Damanhuri E., 1996 "Teknik Pembuangan Akhir", Jurusan Teknik Lingkungan, Fakultas Teknik Sipil \& Perencanaan, ITB

4. Tchobanoglous G., H. Theisen, \& S. A. Vigil, 1993, "Integrated Solid Waste
Management", McGraw-Hill International, Singapore

5. Morton. J., 2005, "World Bank Experience in Landfill Gas and Prospects in Indonesia", A Technical Presentation 